Z Lebensm Unters Forsch (1991) 193:115-118

\title{
Stereoisomere Aromastoffe
}

\section{LI: Stereodifferenzierung chiraler Furanone Möglichkeiten und Grenzen der herkunftsspezifischen Aromastoff-Analyse}

\author{
Günther Bruche ${ }^{1}$, Hans-Georg Schmarr ${ }^{1}$, Andrea Bauer ${ }^{1}$, Armin Mosandl ${ }^{1}$, Adolf Rapp ${ }^{2}$ und Lorenz Engel $^{2}$ \\ 1 Institut für Lebensmittelchemie, Universität Frankfurt, Robert-Mayer-Strasse 7-9, \\ W-6000 Frankfurt/Main, Bundesrepublik Deutschland \\ ${ }^{2}$ Bundesforschungsanstalt für Rebenzüchtung, Geilweilerhof, W-6741 Siebeldingen, Bundesrepublik Deutschland
}

Wir machen unsere Leser darauf aufmerksam, daß der im oben genannten Beitrag mehrfach benutzte Begriff FURANEOL ${ }^{\circledR}$ ein eingetragenes Warenzeichen der Firma Firmenich S.A. Genf ist. Bei FURANEOL ${ }^{\circledR}$ handelt es sich damit nicht um eine chemische Bezeichnung, die frei verwendet werden darf. 